\title{
Inequities in coverage of smokefree outdoor space policies within the United States: school grounds and playgrounds
}

\author{
Christopher Lowrie ${ }^{1}$, Amber L. Pearson ${ }^{1,2,3^{*}}$ (D) and George Thomson ${ }^{2}$
}

\begin{abstract}
Background: Previous studies have found extensive geographic and demographic differences in tobacco use. These differences have been found to be reduced by effective public policies, including banning smoking in public spaces. Smokefree outdoor spaces reduce secondhand smoke exposure and de-normalize smoking.

Methods: After previously publishing a study of smokefree indoor and outdoor space policies, it was brought to the authors' attention that the dataset used in analyses was incomplete (Lowrie et al., BMC Public Health 17:456, 2017). The current manuscript is a corrected version. Here, we include analyses for outdoor space policies. We evaluated regional and demographic differences in the proportion of the population (both adult and child) covered by smokefree outdoor space policies for school grounds and playgrounds enacted in the United States prior to 2014.

Results: Children had a low level of protection in playgrounds and schools (8\% covered nationwide in both settings). Significant differences in coverage were found by ethnicity, region, income, and education $(p<0.001)$. The odds of having a smokefree playgrounds policy was lower for jurisdictions with higher proportions of poor households, households with no high school diploma, whites and the Alaska/Hawaii region. Increased ethnic heterogeneity was found to be a significant predictor of increased odds of having a smokefree playgrounds policy, meaning that diversity is protective, with differential effect by region $(p<0.001)$ - which may relate to urbanicity.

Conclusions: Disparities in smokefree outdoor space policies have potential to exacerbate existing health inequities. A national increase in smokefree outdoor space policies to protect children in playgrounds and schools is a crucial intervention to reduce such inequities.
\end{abstract}

Keywords: Smoking, Inequalities, Smokefree outdoor spaces, Geography

\section{Background}

Tobacco use continues to be a primary global health issue, with over 180 nations committed to reducing smoking as signatories to the Framework Convention on Tobacco Control [1]. Cigarette smokers have shorter lifespans than non-smokers by at least 10 years [2], due to many health issues, including cancer, cardiovascular diseases, and respiratory diseases [3]. The negative effects of cigarette smoking are large and well-documented for most

\footnotetext{
* Correspondence: apearson@msu.edu

This is an addendum to the article available online at https://doi.org/ 10.1186/s12889-018-5602-7.

'Department of Geography, Environment, and Spatial Sciences, Michigan State University, 673 Auditorium Road, East Lansing, MI 48824, USA

2Department of Public Health, University of Otago, Wellington 6021, New Zealand Full list of author information is available at the end of the article
}

countries. In the United States, more people have been prematurely killed by cigarette smoke than in all of the nation's wars combined [2]. In the United Kingdom, 19\% of cancer cases are linked with exposure to cigarette smoke [4]. And in China, alone, approximately 1 million deaths are linked to cigarette smoke each year [5]. Globally, tobacco kills more than 6 million people each year [1].

These impacts are distributed unequally, with consequent inequities. For this work, we adapt a definition of inequalities as 'the different availability of resources to which individuals and groups have access to' [6]. A range of studies have found evidence of inequities in tobacco smoking and secondhand smoke (SHS) exposure $[5,7,8]$, with minorities generally experiencing higher risks related to tobacco. Research in the United States revealed differences in 
likelihood of smoking by ethnicity, which became larger with age [9]. Another study in the United States found that smokefree home policies were more prevalent in the West, and among those making over $\$ 100,000$ and those with graduate degrees [10]. A study in the Southeastern United States found that less-educated citizens were less likely to be covered by smokefree space policies, and that smoking was a predictor of dropping out of high school [11]. In addition to ethnic differences, the likelihood of tobacco addiction has been associated with educational attainment, socioeconomic status, and region $[5,11-13]$. In a study of American twins in the military, cigarette smoking was found to have an association with lower educational attainment [12]. Geographically, in the United States in 2015 the Midwest had the highest prevalence of cigarettes smoking among adults 18 years and older at $18.7 \%$, above the national prevalence of $15.1 \%$, and the southeastern states of West Virginia and Kentucky had prevalences of 26.7 and $26.2 \%$, respectively [8]. These inequities in smoking prevalences by ethnicity, socioeconomic status, and geography suggest drastically different tobacco related risks within America, dependent on circumstances and experience. To counter this, more widespread policies to cover vulnerable populations are needed.

Research has consistently found that denormalizing smoking is an effective way of decreasing smoking prevalence and preventing initial uptake of tobacco use [14-17]. To denormalize smoking is to reduce its social acceptability and the perception of it as a normal activity, thereby promoting quitting and preventing initiation [18]. Research indicates that interventions aimed at reducing tobacco use are more successful if they change what is considered socially 'normal' behavior within the targeted community. Many factors influence the normality of smoking, both positively and negatively. Smoking can be made to seem more normal due to advertisements and efforts by the tobacco industry, which spent $\$ 9$ billion on advertising in 2014, largely aimed at ethnic minorities [19]. Of importance to the current study, smoking can also be denormalized by intelligent outdoor smokefree space policies. These policies reduce smoking in the public view, and have been shown to deter smoking and increase the perception of smoking as socially unacceptable $[20,21]$.

One important area of intervention is tobacco use by children, when lifetime use and addiction is typically established [22]. Smokefree space policies protecting places frequented by children are also important for reducing exposure to SHS. Almost half of children worldwide are regularly exposed to SHS in public spaces [1]. Extensive research has found smokefree space policies to be effective in reducing tobacco smoking and increasing cessation, while improving population health and air quality [23]. In California, smoking bans in homes and perceptions of local smokefree outdoor areas were both found to decrease smoking and increase quit attempts [24]. Across the USA, smokefree indoor policy bans were also found to explain smoking prevalence at the state level [25]. In Ontario, exposure to smoking in restaurants and bar patios was found to decrease the likelihood of a quit attempt [26]. Jurisdictions in North America are increasingly adopting legislation for smokefree public spaces; a study in Canada found that indoor smoking restrictions follow a spatial diffusion pattern, with jurisdictions following examples set by nearby and similar jurisdictions [27].

While indoor smoking bans have been widely enacted since 1975 in the United States [28], outdoor smokefree policies are less common. Despite the compilation of a national database on outdoor smokefree space policies in the United States [29] analysis of these important interventions remains limited. We found few existing national studies in the USA on regional differences in smokefree space policies, or on ethnic, socioeconomic, and educational differences in the populations covered by these policies. Studies have been conducted at the state level (e.g. California [30]), and primarily pertain to indoor space policies or have been limited to outdoor spaces such as parks and beaches [31, 32]. In the latter research, the odds of having a local smokefree parks policy was found to increase with higher percentages of Hispanics, people under the age of 18, Democrats, and recent movers; and to decrease with a higher percentage of older voters, smokers, and non-Hispanic Whites [32]. Additionally, lower odds of having a smokefree space policy at the state level was significantly associated with higher percentages of smokers, and rural counties were found to be less likely to have policy protection than urban counties. Using policy data enacted up to 2009, Gonzales et al. found ethnic differences in coverage by indoor smokefree policies in the USA, with Hispanics and Asians having more coverage than Blacks [33]. After previously publishing a study of smokefree indoor and outdoor space policies, it was brought to the authors' attention that the dataset used in analyses was not complete [34]. The current manuscript is a corrected version and only includes analyses for outdoor space policies.

This research investigated inequalities in coverage by ethnicity, socioeconomic status, educational attainment, and region, for smokefree outdoor space policies for places frequented by children: school grounds and playgrounds. The research questions were: 1) Are there differences in the proportion of the population covered by such smokefree space policies by ethnicity, income, or education?; 2) Are there differences by ethnicity in the proportion of children covered by these policies?; 3) Are there regional differences or geographic patterns in the proportion of the population covered by these policies?; and 4) What is the association between the existence of 
smokefree playgrounds policies and area-level ethnic heterogeneity, income, educational attainment, percentage white, and region?

\section{Methods}

\section{Data sources}

Tobacco control laws data were provided by the American Nonsmokers' Rights Foundation U.S. Tobacco Control Laws Database. This database contained zip code $(n=1574)$, county $(n=279)$, and state $(n=37)$ level data for policies enacted pre-2015 covering outdoor public spaces. Explicit in these data were descriptions of the policies and the spaces covered which were used in our analysis. In total, three groups of restrictions were studied: playgrounds, school grounds, and both playgrounds and school grounds. We excluded smokefree policies covering less frequently visited outdoor spaces and places where less time would be spent (e.g., fairs/festivals, public events, and parking lots). State and county policies were applied to all zip codes within the jurisdiction to allow for analysis at the zip code level, resulting in a total of 21,477 zip codes with policies (66\% of the US total zipcodes). This builds on the work done and methodology used by Hood et al. [32], in which research was conducted at the county level. By using zip codes, we hoped to obtain a higher resolution of the differences between jurisdictions.

Demographic data were obtained from the US Census (2010) and included age, ethnicity, educational attainment, and income at the zip code level. Income data was used to calculate income quartiles. Each zip code was assigned to one of six regions, based on the state in which it is located (Fig. 1). By doing this, we hoped to improve upon the work done by Gonzalez et al. [32] by updating their 2009 analyses on ethnic inequalities and extending analyses to examine socioeconomic, educational, and regional inequalities. Ethnic heterogeneity was calculated as 1 minus the sum across ethnic groups of their respective squared proportion, as described by Wadsworth and Kubrin [35], and a binary high versus low ethnic heterogeneity variable was created using the mean as the cutoff.

\section{Statistical and geographic methods}

To address the first three research questions, a chi-squared test was used to test for significant differences in counts of population subgroups covered by each of the three types of smokefree outdoor space policies. Analysis was conducted by ethnicity (for the total population and for children $<15$ years old), income and educational attainment (for adults $\geq 25$ years old), and region (for the total population). To assess geographic patterns in policy adoption, data were imported into ESRI ArcGIS version 10.2 and maps for all zip codes, delineated by region, were created.

To address the fourth research question, we fitted a mixed effects logistic regression model, to test which demographic characteristics were associated with smokefree playgrounds policies. We chose not to fit a model for whether or not a place has a school grounds and playgrounds policy, due to both very low levels of such policies and extreme differences in regions, which would lead to model instability. In our model, the dependent variable of interest was a binary measure of whether

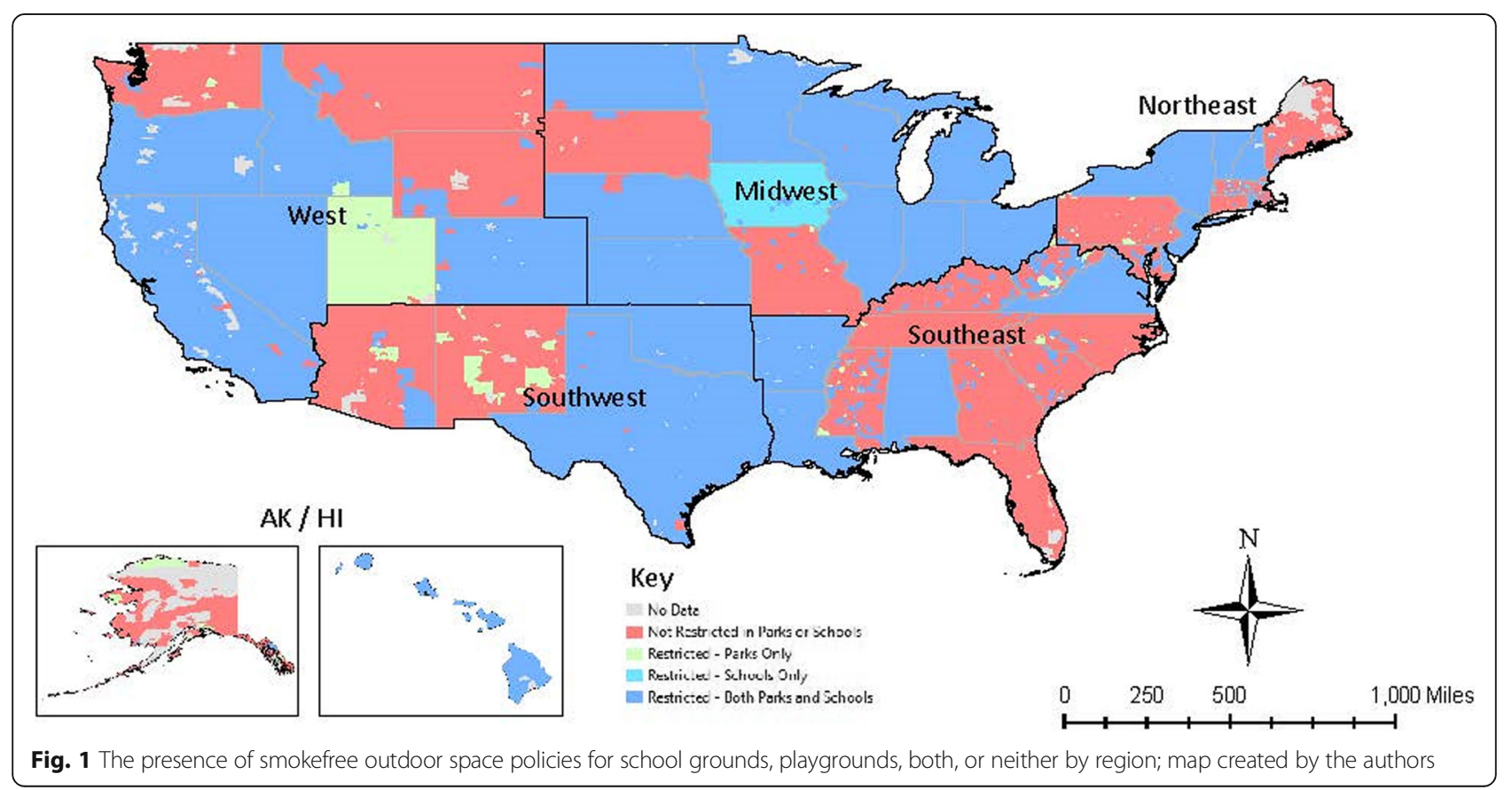


each zip code had a policy protecting playgrounds. We also investigated whether interaction terms improved the model fit, using the likelihood ratio test. Specifically, we examined interactions between ethnic heterogeneity and region, and between percentage black and region, and compared the log likelihoods obtained from models including and excluding these interaction parameters. Thus, our final model included the following independent variables: education, high/low ethnic heterogeneity, percentage white, income, and region, as well as an interaction term between ethnic heterogeneity and region. We accounted for non-independence in zip code policy status within state clusters by fitting a hierarchical regression model including random effects at the state level. All statistical analyses were conducted using Stata v14 software.

\section{Results}

Of the approximately 350 million people living in the United States in 2014, only 9\% had smokefree outdoor space policy protection for both school grounds and playgrounds within their home zip code (Table 1). Higher proportions of the population were covered under smokefree policies just for playgrounds (28\%), with far lower coverage for school grounds (18\%). A significant difference was observed between ethnic groups for the proportion covered $(p<0.001)$. Whites followed by Blacks had the lowest proportion of coverage, with only 8 and $9 \%$, respectively, of the population living in zip codes with coverage for both outdoor spaces, and Asians had the highest (13\%). The differences were even greater for just playgrounds, with Asian (51\%) and Hispanic (40\%) coverage much higher than for Whites (23\%) and Blacks (22\%). The proportions of children covered followed the same trends as the total population, with only $8 \%$ of children in the US living in zip codes with smokefree policies for school grounds and playgrounds. We noticed a difference in coverage by wealth, whereby those with the highest income $(>\$ 75 \mathrm{k})$ had a higher proportion of the population covered by these policies (10\%) compared to the middle and lowest incomes (8\%). These differences were statistically significant $(p<0.001)$. Again, the differences were even greater for just playgrounds, with $29 \%$ coverage for the highest income, compared to $22 \%$ for the lowest $(<\$ 25 \mathrm{k})$. A significant gradient was found for educational attainment, whereby the highest level of education (graduate degree) had the highest proportion covered by both smokefree space policies (11\%) and the lowest levels of education (no high school diploma) had the lowest proportion (7\%). There were larger differences for just playgrounds, with 29 and $12 \%$ coverages for the highest and lowest education levels.

By region, the differences were stark. The Northeast had a much higher rate of coverage for smokefree
Table 1 Percentage population covered by smokefree school grounds and playgrounds policies, by subgroups

\begin{tabular}{|c|c|c|c|}
\hline & Playgrounds & $\begin{array}{l}\text { School } \\
\text { grounds }\end{array}$ & $\begin{array}{l}\text { Both playgrounds } \\
\text { and school grounds }\end{array}$ \\
\hline \multicolumn{4}{|l|}{ Ethnicity - Total population } \\
\hline Total & 28 & 18 & 9 \\
\hline Asian & 51 & 21 & 13 \\
\hline Black & 22 & 18 & 10 \\
\hline Hispanic & 40 & 16 & 9 \\
\hline White & 23 & 18 & 8 \\
\hline Other & 44 & 19 & 12 \\
\hline \multicolumn{4}{|l|}{ Ethnicity - Children $<15$ years } \\
\hline Total & 28 & 17 & 8 \\
\hline Asian & 48 & 21 & 12 \\
\hline Black & 21 & 18 & 10 \\
\hline Hispanic & 38 & 15 & 7 \\
\hline White & 22 & 18 & 8 \\
\hline Other & 43 & 18 & 11 \\
\hline \multicolumn{4}{|l|}{ Income $e^{a}$} \\
\hline$<\$ 25,000$ & 22 & 17 & 8 \\
\hline$\$ 25,000-\$ 75,000$ & 23 & 17 & 8 \\
\hline$>\$ 75,000$ & 29 & 20 & 10 \\
\hline \multicolumn{4}{|l|}{ Educational Attainment ${ }^{a}$} \\
\hline No high school diploma & 12 & 19 & 7 \\
\hline High school diploma & 22 & 18 & 9 \\
\hline Bachelors & 28 & 20 & 10 \\
\hline Masters or Doctorate & 29 & 21 & 11 \\
\hline \multicolumn{4}{|l|}{ Region - Total population } \\
\hline $\mathrm{AK} / \mathrm{HI}$ & 11 & $\sim 0$ & $\sim 0$ \\
\hline Midwest & 7 & 6 & 1 \\
\hline Northeast & 43 & 51 & 39 \\
\hline Southeast & 8 & 10 & 1 \\
\hline Southwest & 3 & $\sim 0$ & $\sim 0$ \\
\hline West & 66 & 20 & 2 \\
\hline
\end{tabular}

${ }^{\text {a }}$ Calculated for the population over 25 years old

$P$-values calculated using Pearson's $X^{2}$ statistic - all differences $p<0.001$

policies for both school grounds and playgrounds, compared to the other regions, with $39 \%$ of the population covered; no other region had more than $2 \%$ of the population covered. Virtually no coverage for both school grounds and playgrounds was observed in AK/ HI, and the Southwest. For playgrounds (which tended to have higher levels of coverage overall), the West (66\%) and the Northeast (43\%) had higher levels, compared to all other regions $(<12 \%)$ (Table 1 and Fig. 1). The Northeast had significantly higher coverage at school grounds (51\%), compared to other regions $(p<0.001)$. 
Visually, there were clear geographic patterns in smokefree outdoor space policies, whereby there appeared to be generally low consistency at the state-level (Fig. 1). Clusters of jurisdictions which adopted policies restricting smoking on both school grounds and playgrounds can be observed, particularly in Mississippi, New Jersey, Colorado, and Oregon. New York is the only state covered for both types of outdoor areas. Only 10 states had a state policy on either playgrounds or school grounds.

In the mixed effects logistic regression model (Table 2), all independent variables and the interaction term were found to be significant predictors of whether a smokefree playgrounds policy had been adopted. We observed a clear wealth gradient whereby odds increased with wealth (, after adjustment for other covariates. The highest income group had more than three times the odds of having a policy, compared to the lowest income group (OR 3.44, 95\%CI: 2.08-4.40). We found small, significant effects for both percentage of the population without a high school diploma and

Table 2 Hierarchical logistic regression model results

\begin{tabular}{|c|c|c|c|c|c|}
\hline \multicolumn{2}{|c|}{$\begin{array}{l}\text { Predicting the presence of a } \\
\text { smokefree policy for playgrounds }\end{array}$} & \multirow{2}{*}{$\begin{array}{l}\text { OR } \\
\mathbf{2 . 0 8}\end{array}$} & \multicolumn{2}{|l|}{$95 \% \mathrm{Cl}$} & \multirow{2}{*}{$\begin{array}{l}p^{*} \\
<0.001\end{array}$} \\
\hline & High Heterogeneity & & 1.40 & 3.10 & \\
\hline & Percent White & 0.99 & 0.98 & 0.99 & $<0.001$ \\
\hline \multirow{4}{*}{$\begin{array}{l}\text { Income } \\
\text { Quantiles }\end{array}$} & 1 - Lowest & ref & & & $<0.001$ \\
\hline & 2 & 1.27 & 1.01 & 1.60 & \\
\hline & 3 & 1.70 & 1.35 & 2.15 & \\
\hline & 4 - Highest & 3.44 & 2.68 & 4.40 & \\
\hline $\begin{array}{l}\text { Educational } \\
\text { Attainment }\end{array}$ & $\begin{array}{l}\% \text { without a High } \\
\text { School Diploma }\end{array}$ & 0.98 & 0.97 & 0.99 & $<0.001$ \\
\hline \multirow[t]{6}{*}{ Region } & West & ref & & & 0.043 \\
\hline & $\mathrm{AK} / \mathrm{HI}$ & $<0.001$ & $<0.001$ & $<0.001$ & \\
\hline & Midwest & 0.09 & 0.01 & 1.37 & \\
\hline & Southwest & 0.04 & 0.001 & 1.87 & \\
\hline & Northeast & 4.15 & 0.27 & 63.07 & \\
\hline & Southeast & 0.52 & 0.04 & 7.57 & \\
\hline \multirow[t]{7}{*}{$\begin{array}{l}\text { Diversity } \\
\text { X Region }\end{array}$} & $\begin{array}{l}\text { High Heterogeneity. } \\
\text { West }\end{array}$ & ref & & & $<0.001$ \\
\hline & $\begin{array}{l}\text { High Heterogeneity. } \\
\text { AK/HI }\end{array}$ & $<0.001$ & $<0.001$ & $<0.001$ & \\
\hline & $\begin{array}{l}\text { High Heterogeneity. } \\
\text { Midwest }\end{array}$ & 1.98 & 1.22 & 3.19 & \\
\hline & $\begin{array}{l}\text { High Heterogeneity. } \\
\text { Southwest }\end{array}$ & 1.12 & 0.48 & 2.63 & \\
\hline & $\begin{array}{l}\text { High Heterogeneity. } \\
\text { Northeast }\end{array}$ & 0.95 & 0.59 & 1.52 & \\
\hline & $\begin{array}{l}\text { High Heterogeneity. } \\
\text { Southeast }\end{array}$ & 0.63 & 0.39 & 1.01 & \\
\hline & Constant & 0.08 & 0.01 & 0.65 & 0.018 \\
\hline
\end{tabular}

${ }^{*}$ Overall $p$-values for categorical variables calculated using likelihood ratio test Bold indicates significance at the $p<0.05$ level percentage white, whereby higher percentages were associated with lower odds of having a policy. We also found that the effect of high ethnic heterogeneity differed significantly by region, but was consistently positively associated with having a policy $(p<0.001)$. For example, the ratio of odds of having a policy in zip codes with high versus low heterogeneity was highest in the Midwest (OR 3.00), followed by the Southwest (OR 2.34), the West (2.08), the Northeast (OR 1.99), the Southeast (OR 1.31) and no real difference in Alaska/ Hawaii $(\mathrm{OR} \sim 1.00)$.

\section{Discussion}

Our findings confirm that there are stark differences in smokefree outdoor space policy coverage in places frequented by children based on ethnicity, socioeconomic status, educational attainment, and region. A serious lack of smokefree policy protection exists for children in the United States; only $8 \%$ of children in the United States live in zip codes with both smokefree playgrounds and school grounds. This low joint coverage is regardless of ethnicity.

It is important to eliminate exposure to tobacco use for children for three main reasons. Reducing exposure to tobacco use serves to reduce both the social normality and acceptability of smoking, as well as exposure to SHS. Furthermore, ethnic inequalities in coverage of playground policies may contribute to long-term health inequalities. The differences in the coverage spread for playgrounds (where there was a wide coverage variance by ethnicity) and school grounds (where there was a much narrower spread) may be related to different authorities covering the different types of child-related areas. Although playground and school ground policies are comparatively rare, these policies have been supported by $76 \%$ or more of the public in surveys within the USA since 2005 [36].

Regional differences in the coverage of smokefree space policies were large - and the effect of ethnic heterogeneity varied. Virtually no coverage for both school grounds and playgrounds was observed in Alaska/Hawaii and the Southwest, with all other regions below 3\%, except for the Northeast. Considering the importance of smokefree outdoor space policy in reductions in tobacco prevalence and normality, it is crucial to address regional differences in order to continue to see equitable declines in tobacco use. These large regional discrepancies help to explain some of the differences in coverage by ethnicity. There is a large discrepancy between the Northeast and the rest of the United States, in the coverage for both playgrounds and school grounds, which warrants further study. The Northeast had coverage at a rate of $39 \%$ (largely due to New York State), compared to less than $3 \%$ for the rest of the country. 
The effect of ethnic heterogeneity was significantly different by region, but was consistent in that more heterogeneous zip codes had higher odds of coverage in every region. The Midwest showed the largest effect of ethnic heterogeneity, with diverse zip codes over three times more likely to have a smokefree playgrounds policy.

This research found evidence of inequalities in smokefree outdoor space policy coverage by socioeconomic status and by educational attainment. In particular, the odds of having a policy covering playgrounds was found to decrease as the proportion of the population without a high school diploma increased, and as the average income of the zip code decreased. These differences illustrate ongoing shortages in protection for the United States' poorest and least educated citizens, which begin at birth and impact the likelihood of smoking and quitting.

\section{Research implications}

Considering the inequities observed in this study, the forces which impact policy adoption are an important next step to research. Successful adoption of policies is likely due in part to differing political climates between areas, as well as efforts by both the tobacco industry and by smokefree advocates [37-39]. Our speculation is that smokefree advocate organizations have a greater relative impact in cities compared to tobacco marketing. Urban areas are known to lean towards voting for Democrats, have more robust public health systems, and generally be more accepting of government oversight and legislature [32, 40, 41]. Future research could explore relationships between population density and policy adoption.

\section{Policy implications}

In order to further declines in smoking and uptake among youth, policies must address the low level of coverage in places frequented by children. Considering the impact these policies have on the perceptions of smoking which children develop, as well as the low existing level of coverage nationally, policies aimed at protecting children in school grounds and playgrounds may have a large impact on smoking trends, now and into the future.

\section{Conclusion}

This research revealed clear inequalities in the coverage of smokefree outdoor space policies, specifically ethnic, income, educational and regional inequalities. Inequalities in the banning of smoking in areas frequented by children may perpetuate the normality of smoking within subgroups of the United States' population, and thus reinforce disparities in the negative impacts of exposure to smoking. Our regression results indicate that income inequalities between places may influence smokefree policies, and that policy coverage differences have real potential to exacerbate existing health inequalities. Legislative coverage of smokefree outdoor spaces is an important, cost-effective option to protect adults and children from SHS exposure and the normality of smoking. But, if not implemented equitably, tobacco-related health inequities may persist.

\section{Acknowledgements}

The tobacco control laws data were provided by the American Nonsmokers' Rights Foundation U.S. Tobacco Control Laws Database@.

\section{Funding}

This work received funding support from Michigan State University's Provost Undergraduate Research Initiative. The funding body was not involved in the design of the study, collection of data, analysis or interpretation of data or the writing of the manuscript.

\section{Availability of data and materials \\ The 2010 census data used in this study is publically-available from the US government and available for download at: https://www.census.gov/programs- surveys/decennial-census/data/datasets.2010.html. Smokefree policy data is both freely available (http://www.no-smoke.org/goingsmokefree.php?id=519\#outdoor) and available for purchase in a compiled dataset form from American Non- smokers' Rights Foundation.}

Authors' contributions

GT and AP designed the study. GT obtained the policy data. CL obtained the census data. AP supervised analyses and guided interpretation, conducted by $C L$. All authors read and approved the manuscript.

Ethics approval and consent to participate

Not applicable.

\section{Competing interests}

The authors declare that they have no competing interests.

\section{Publisher's Note}

Springer Nature remains neutral with regard to jurisdictional claims in published maps and institutional affiliations.

\section{Author details}

${ }^{1}$ Department of Geography, Environment, and Spatial Sciences, Michigan State University, 673 Auditorium Road, East Lansing, MI 48824, USA.

${ }^{2}$ Department of Public Health, University of Otago, Wellington 6021, New Zealand. ${ }^{3}$ Environmental Science and Policy Program, Michigan State University, East Lansing, Ml 48824, USA.

Received: 20 October 2017 Accepted: 24 May 2018

Published online: 14 June 2018

References

1. World Health Organization, Tobacco: fact sheet N³39. 2015.

2. US Department of Health and Human Services, The health consequences of smoking - 50 years of progress. A report of the surgeon general. 2014.

3. Boyle P. Tobacco and public health: science and policy. USA: Oxford University Press; 2004

4. Parkin D. 1. The fraction of cancer attributable to lifestyle and environmental factors in the UK in 2010. Br J Cancer. 2011;105:S2-5.

5. Barnett R, Pearce J, Moon G. Community inequality and smoking cessation in New Zealand, 1981-2006. Soc Sci Med. 2009;68(5):876-84.

6. Moore S, Stewart S, Teixeira A. Decomposing social capital inequalities in health. J Epidemiol Community Health. 2014;68(3):233-8.

7. Jamal A, King BA, Neff $\sqcup$, Whitmill J, Babb SD, Graffunder CM. Current Cigarette Smoking Among Adults - United States, 2005-2015. MMWR Morb Mortal Wkly Rep. 2016;65:1205-11. https://doi.org/10.15585/mmwr.mm6544a2. 
8. Nguyen KH, Marshall L, Brown S, Neff L. State-Specific Prevalence of Current Cigarette Smoking and Smokeless Tobacco Use Among Adults — United States, 2014. MMWR Morb Mortal Wkly Rep. 2016;65:1045-51. https://doi. org/10.15585/mmwr.mm6539a1.

9. Lawrence EM, Pampel FC, Mollborn S. Life course transitions and racial and ethnic differences in smoking prevalence. Adv Life Course Res. 2014;22:27-40.

10. Kruger J, et al. Smoke-free home and vehicle rules by tobacco use status among US adults. Prev Med. 2015;78:9-13.

11. Aloise-Young PA, Cruickshank C, Chavez EL. Cigarette smoking and perceived health in school dropouts: a comparison of Mexican American and non-Hispanic white adolescents. J Pediatr Psychol. 2002;27(6):497-507.

12. Grant JD, et al. Associations of alcohol, nicotine, cannabis, and drug use/ dependence with educational attainment: Evidence from Cotwin-Control Analyses. Alcohol Clin Exp Res. 2012;36(8):1412-20.

13. Reid JL, Hammond D, Driezen P. Socio-economic status and smoking in Canada, 1999-2006: has there been any progress on disparities in tobacco use? Can J Public Health. 2010;101(1):73-8.

14. Leonardi-Bee J, Jere ML, Britton J. Exposure to parental and sibling smoking and the risk of smoking uptake in childhood and adolescence: a systematic review and meta-analysis. Thorax. 2011; https://doi.org/10.1136/thx.2010.153379.

15. Baha M, Le Faou A-L. Smokers' reasons for quitting in an anti-smoking social context. Public Health. 2010;124(4):225-31.

16. DiFranza JR, et al. Tobacco promotion and the initiation of tobacco use: assessing the evidence for causality. Pediatrics. 2006;117(6):e1237-48.

17. MacFadyen L, Hastings G, MacKintosh AM. Cross sectional study of young people's awareness of and involvement with tobacco marketing. BMJ. 2001; 322(7285):513-7.

18. Pierce JP, White VM, Emery SL. What public health strategies are needed to reduce smoking initiation? Tob Control. 2012;21(2):258-64.

19. Prevention CfDCa, Tobacco industry marketing. 2016

20. Klein EG, Bernat DH, Forster JL. Young adult perceptions of smoking in outdoor park areas. Health Place. 2012;18(5):1042-5.

21. Albers $A B$, et al. Effect of smoking regulations in local restaurants on smokers' anti-smoking attitudes and quitting behaviours. Tob Control. 2007;16(2):101-6.

22. US Department of Health and Human Services, Preventing Tobacco use among Youth and Young Adults: A Report of the Surgeon General: Executive Summary. 2012.

23. Hahn EJ. Smokefree legislation a review of health and economic outcomes research. Am J Prev Med. 2010;39(6):S66-76.

24. Zablocki RW, et al. Smoking ban policies and their influence on smoking behaviors among current California smokers: a population-based study. Prev Med. 2014;59:73-8.

25. Chahine T, Subramanian S, Levy Jl. Sociodemographic and geographic variability in smoking in the US: a multilevel analysis of the 2006-2007 current population survey, tobacco use supplement. Soc Sci Med. 2011;73(5):752-8.

26. Chaiton $M$, et al. Exposure to smoking on patios and quitting: a population representative longitudinal cohort study. Tob Control. 2014; https://doi.org/ 10.1136/tobaccocontrol-2014-051761.

27. Nykiforuk Cl, Eyles J, Campbell HS. Smoke-free spaces over time: a policy diffusion study of bylaw development in Alberta and Ontario, Canada. Health Soc Care Commun. 2008;16(1):64-74

28. Hyland A, Barnoya J, Corral JE. Smoke-free air policies: past, present and future. Tob Control. 2012;21(2):154-61

29. Foundation AN-SR, U.S. Tobacco Control Laws Database: Research Applications. 2010.

30. California ALAi, Becoming a Policy Wonk on Comprehensive Outdoor Secondhand Smoke Ordinances: Answers to Tough Questions from Opponents and Elected Officials. 2014

31. Bayer R, Bachynski KE. Banning smoking in parks and on beaches: science, policy, and the politics of denormalization. Health Aff. 2013;32(7):1291-8.

32. Hood NE, et al. Community characteristics associated with smokefree park policies in the United States. Nicotine Tob Res. 2014;16(6):828-35.

33. Gonzalez M, et al. Strong smoke-free law coverage in the United States by race/ethnicity: 2000-2009. Am J Public Health. 2013;103(5):e62-6.

34. Lowrie C, Pearson AL, Thomson G. Inequities in coverage of smokefree space policies within the United States. BMC Public Health. 2017;17(1):456.

35. Wadsworth T, Kubrin CE. Structural factors and black interracial homicide: new examination of the causal process. Criminology. 2004;42(3):647-72.

36. Thomson $\mathrm{G}$, et al. Attitudes to smoke-free outdoor regulations in the USA and Canada: a review of 89 surveys. Tob Control. 2015; https://doi.org/10. 1136/tobaccocontrol-2015-052426.
37. Rayens MK, et al. Political climate and smoke-free laws in rural Kentucky communities. Policy Polit Nurs Pract. 2012;13(2):90-7.

38. Satterlund TD, et al. Barriers to adopting and implementing local-level tobacco control policies. J Community Health. 2011;36(4):616-23.

39. Tung GJ, et al. Political factors affecting the enactment of state-level clean indoor air laws. Am J Public Health. 2014;104(6):e92-7.

40. Harris JK, Mueller NL. Policy activity and policy adoption in rural, suburban, and urban local health departments. J Public Health Manag Pract. 2013; 19(2):E1-8.

41. Rosenblatt RA, Casey S, Richardson M. Rural-urban differences in the public health workforce: local health departments in 3 rural western states. Am J Public Health. 2002;92(7):1102-5.

\section{Ready to submit your research? Choose BMC and benefit from:}

- fast, convenient online submission

- thorough peer review by experienced researchers in your field

- rapid publication on acceptance

- support for research data, including large and complex data types

- gold Open Access which fosters wider collaboration and increased citations

- maximum visibility for your research: over $100 \mathrm{M}$ website views per year

At BMC, research is always in progress.

Learn more biomedcentral.com/submissions 